Психология. Журнал Высшей школы экономики.

2011. T. 8, № 1. С. 150-156.

Короткие сообщения

\title{
СТРУКТУРНАЯ СОЦИАЛЬНО-КОГНИТИВНАЯ МОДЕЛЬ ЛИДЕРСКОГО ПОТЕНЦИАЛА ОРГАНИЗАЦИОННОГО ЛИДЕРА
}

\author{
О.В. ЕВТИХОВ
}

\begin{abstract}
Резюме
В статье на основе теоретического анализа феномена лидерства применительно к менеджменту описана авторская социально-когнитивная модель лидерского потенциала организачионного лидера, которая может быть полезна при решении задачи развития лидерского компонента в управленческой деятельности руководителя.
\end{abstract}

Ключевые слова: лидерство, руководитель, лидерский потенциал.

Проблема определения структуры и компонентов лидерского потенциала организационного лидера актуальна в контексте решения задачи повышения эффективности профессиональной деятельности руководителя. Несмотря на то, что интерес исследователей к лидерскому потенциалу среди ученых и просто любопытствующих людей в настоящее время высокий, в результате проведенного анализа научных публикаций нам не удалось обнаружить прикладную концептуальную модель, описывающую структуру и компоненты лидерского потенциала руководителя, для определения направления практической работы по его развитию применительно к конкретной социальной группе (подразделению). Многие работы, посвященные исследованию лидерского потенциала, описывают лишь компоненты структуры, не отражая актуальной лидерской специфики и контекста. Так, большинство работ ориентированы на описание и развитие качеств лидера, не рассматривают лидерство как социальный феномен, поведение и восприятие лидера последователями, а также условия, в которых реализуются процессы лидерства. Например, М.Н. Емельянова в структуре лидерского потенциала 
выделяет следующие сферы развития личности: психофизиологическую (тип темперамента, здоровье), социальную (коммуникативные умения, самостоятельность, адаптивное поведение, инициатива и исполнительность, самооценка), интеллектуальную (развитие речи и дивергентного мышления) и эмоциональную (умение понимать эмоциональное состояние другого человека и умение сопереживать) (Емельянова, 2001). Е.П. Ходаева выделяет следующие психологические составляющие лидерского потенциала применительно к политику: силу личности, способность оказывать влияние на окружающих, способность к управленческой деятельности, экстравертированность, коммуникабельность, активность, интеллектуальные способности, интуицию, гибкость и пластичность, целеустремленность (Ходаева, 2002).

Не принижая ценности представленных работ, следует отметить, что описываемые в них компоненты структуры «лидерского потенциала» если и описывают потенциал, то необязательно лидера, а скорее любого человека с прицелом на то, что он «потенциально» может стать лидером. Соответственно многие из них ориентированы на разработку различных развивающих программ, и в них прорабатываются вопросы развития потенциально полезных качеств «будущего» лидера.

В нашем случае мы поставили задачу разработать социально-психологическую модель, позволяющую повышать лидерский потенциал руководителей в конкретных социальных группах. На наш взгляд, каждый структурный компонент модели ли- дерского потенциала организационного лидера должен обеспечивать возможность руководителя занять лидерское положение в группе и использовать лидерский ресурс в управленческой деятельности.

Прежде чем перейти к рассмотрению компонентов и структуры лидерского потенциала организационного лидера, необходимо внести ясность в понятийный аппарат и уточнить сами понятия: потенциал и лидерский потенциал. Слово «потенциал» является производным от латинского potentia (потенция), которое трактуется в толковом словаре русского языка С.И. Ожегова и Н.Ю. Шведовой как возможность, т.е. то, что существует в скрытом виде и может проявиться в соответствующих условиях (Ожегов, 1999). Иными словами, потенциал есть некая возможность, сила, включающая в себя источники и средства, которые могут быть использованы для решения какой-либо задачи, достижения определенной цели. Применительно к лидерству потенциал (лидерский потенциал) в обобщенном виде обычно рассматривается как возможность и готовность индивида к эффективному лидерскому поведению. Так, М.В. Кирсанов лидерский потенциал представляет как социально-психологическую характеристику личности, отражающую и ситуационно обусловленную, и не зависящую от ситуации способность индивида к успешному осуществлению лидерства (Кирсанов, 2003). И.В. Дрыгина под лидерским потенциалом представляет качественную характеристику личности, отражающую совокупность внутренних потребностей, возможностей, ценностного отношения, 
средств, способствующих достижению такого уровня интеграции компетентности, ответственности, активности и коммуникативности, который обеспечивает ее ведущее влияние на членов группы при совместном решении задач в различных областях жизнедеятельности (Дрыгина, 2004).

На наш взгляд, так как в процессе лидерства участвуют две стороны «лидер» и «последователи», каждая из которых, так или иначе, воспринимает ситуацию лидерского взаимодействия и совершает определенные действия и поступки в определенных социально-психологических условиях, - то и в определении лидерского потенциала руководителя как организационного лидера полезно отразить следующие содержательные «маркеры»:

- лидерские качества (компетенции) лидера обеспечивают эффективность лидерства;

- особенности восприятия лидера последователями обеспечивают принятие последователями руководителя в качестве лидера;

- условия осуществления лидерства определяют возможности проявления лидерства.

Учитывая результаты семантического анализа понятия «потенциал» и описанные выше «маркеры», можно дать следующее определение лидерскому потенциалу руководителя: лидерский потенииал руководителя в социальной группе (подчиненном подразделении) включает совокупность качеств, условий проявления, а также особенности его восприятия данной группой, которые определяют возможности руководителя занять лидерское положение в группе и успешность использования им определенного ресурса в практике управления.

Исходя из сущностных характеристик и данного нами определения «лидерского потенциала» в его структуре применительно к организационному лидерству необходимо выделять следующие базовые компоненты:

1) когнитивный компонент лидера включает его Я-концепцию и профессионально-управленческое мировоззрение;

2) компетентностно-поведенческий компонент лидера включает комплекс индивидуально-личностных, социальных и организационно-управленческих качеств, обеспечивающих эффективность осуществления руководителем лидерских функций;

3) когнитивный компонент последователей включает образ (имидж) руководителя как организационного лидера в восприятии последователей;

4) поведенческий компонент последователей включает их психологическую готовность и способность осуществлять «последовательское» поведение;

5) организационно-управленческие и социально-психологические условия проявления лидерства включают комплекс организационных и социальных условий, в той или иной степени способствующих проявлению организационного лидерства в организации (см. таблицу).

На наш взгляд, когнитивным компонентом, обусловливающим поведение лидера и особенности его взаимодействия с последователями, является когнитивная картина мира лидера (мировоззрение), включающая 
Социально-когнитивная модель лидерского потенциала организационного лидера

\begin{tabular}{|c|c|c|}
\hline \multirow{3}{*}{ 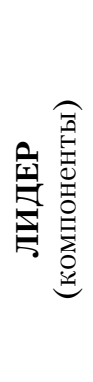 } & \multirow[b]{2}{*}{ Когнитивный } & Я-КОНЦЕПЦИЯ ЛИДЕРА \\
\hline & & $\begin{array}{c}\text { ПРОФЕССИОНАЛЬНО-УПРАВЛЕНЧЕСКОЕ } \\
\text { МИРОВОЗЗРЕНИЕ ЛИДЕРА }\end{array}$ \\
\hline & $\begin{array}{c}\text { Компетентностно- } \\
\text { поведенческий }\end{array}$ & $\begin{array}{c}\text { КОМПЛЕКС ЛИДЕРСКИХ КАЧЕСТВ, } \\
\text { ОБЕСПЕЧИВАЮЩИХ ЭФФЕКТИВНОЕ ЛИДЕРСКОЕ } \\
\text { ПОВЕДЕНИЕ ОРГАНИЗАЦИОННОГО ЛИДЕРА }\end{array}$ \\
\hline & $\begin{array}{r}\text { ОРГА } \\
\text { И СОЦИАЛЬНО-1 } \\
\text { ОР }\end{array}$ & $\begin{array}{l}\text { ЗАЦИОННО-УПРАВЛЕНЧЕСКИЕ } \\
\text { ІХОЛОГИЧЕСКИЕ УСЛОВИЯ ПРОЯВЛЕНИЯ } \\
\text { ИЗАЦИОННОГО ЛИДЕРСТВА }\end{array}$ \\
\hline 疍 & Когнитивный & $\begin{array}{c}\text { ВОСПРИЯТИЕ ПОСЛЕДОВАТЕЛЯМИ } \\
\text { РУКОВОДИТЕЛЯ } \\
\text { КАК ОРГАНИЗАЦИОННОГО ЛИДЕРА } \\
\text { (лидерскИй образ руководителя) }\end{array}$ \\
\hline 哟 & $\begin{array}{l}\text { Компетентностно- } \\
\text { поведенческий }\end{array}$ & $\begin{array}{c}\text { ПСИХОЛОГИЧЕСКАЯ ГОТОВНОСТЬ К ПОВЕДЕНИЮ } \\
\text { В РОЛИ ПОСЛЕДОВАТЕЛЕЙ }\end{array}$ \\
\hline
\end{tabular}

совокупность представлений лидера о себе, окружающем мире и своем месте в этом мире. Когнитивная картина мира лидера во многом предопределяет его «стиль жизни» и является ключом к пониманию осуществляемого им поведения. В контексте рассматриваемой проблемы в качестве основных компонентов картины мира лидера мы выделили следующие: а) «лидерская Я-концепция»: совокупность представлений лидера о себе и своем месте в окружающем социальном мире. Она тесно связана с такими понятиями, как самооценка, социальная ориентация, жизненные цели и притязания; б) «профессионально-управленческое мировоззрение лидера» - представления лидера об окружающем мире, включающая особенности восприятия им внешней действительности, социальные установки и принципы взаимодействия с окружающими людьми. Обе представленные «когнитивные схемы» неразрывно взаимосвязаны, обеспечивают и дополняют друг друга. На наш взгляд, развитие лидерского потенциала руководителя как организационного лидера должно быть связано не просто с развитием лидерских умений и навыков, но и с формированием лидерской Я-концепции и профессионально-управленческого мировоззрения, обеспечивающих проявление соответствующего лидерского поведения в определенных ситуациях.

Компетентностно-поведенческий компонент лидера опосредованно 
раскрывается в его лидерских качествах. Хотя теория лидерских черт была неоднократно раскритикована, ни у кого не вызывает сомнения, что для успешного становления и осуществления лидер должен обладать определенными качествами. Однако перечень этих качеств во многом зависит от особенностей группы, специфики решаемых ею профессиональных задач и др. Поэтому процесс разработки различных специализированных перечней и моделей лидерских качеств продолжает оставаться актуальным. Наличие подобных «профессиограмм» лидера необходим в процессе профессионального психологического отбора кандидатов на руководящие должности и психологического сопровождения профессиональной деятельности руководителей, в том числе их оценки и развития.

Когнитивным компонентом последователей, являющимся структурным компонентом лидерского потенциала руководителя, является его имидж, т.е. интегрированный образ руководителя, воспринимаемый последователями как лидерский. Именно восприятие последователями руководителя обуславливает их отношение к нему как лидеру и особенности взаимодействия с ним. Компетнтностно-поведенческим компонентом последователей, вносящим свой вклад в лидерский потенциал руководителя как организационного лидера и предопределяющим успешность использования лидерского ресурса в практике управления, являются способность и желание подчиненных сотрудников осуществлять «последовательское» поведение во взаимодействии с лидером.
Как отмечал Р. Гринлиф, быть хорошими последователями так же почетно, как и быть хорошим лидером. И эффективному поведению в роли последователя можно и нужно обучаться. Да и сам организационный лидер, как правило, является чьим-то последователем (Greenleaf, 1991). Перенос последователями на лидера части личной активности в области принятия решений, организации и контроля совместной деятельности, их готовность к поддерживающему лидера поведению, а в определенной степени и к подчинению, безусловно, являются важными структурными компонентами лидерского потенциала организационного лидера. Без этого эффективность взаимодействия лидера и последователей, а также эффективность лидерства как процесса значительно снижаются.

Важным условием формирования и реализации лидерского потенциала руководителя как организационного лидера является формирование в организации соответствующих организационно-управленческих и социально-психологических условий, обеспечивающих возможность проявления руководителем организационного лидерства и запечатления его лидерского образа в восприятии сотрудников. Несомненно, что условия и возможности для проявления организационного лидерства различаются у руководителей разных управленческих уровней, а также зависят от специфики решаемых организацией (подразделением) профессиональных задач. Так, Л. Джуэлл прямо указывает, что бывают ситуации, которые препятствуют появлению предпосылок социального 
лидерства в контексте конкретной организации. Например, в случае выполнения постоянных, рутинных заданий начальникам нет необходимости брать на себя роль лидеров. Не отличающиеся гибкостью организации, которые ограничивают возможности руководителей влиять на распределение вознаграждений, не создают предпосылок для лидерского поведения (Джуэлл, 2001). В ряду основных условий формирования и реализации лидерского потенциала руководителя как организационного лидера мы выделили следующие:

а) перцептивно-информационная доступность руководителя для подчиненных сотрудников. Эта возможность может проявляться в регулярности осуществления руководителем таких организационно-управленческих форм взаимодействия руководителя с подчиненными, как проведение совещаний, собраний, а также различных корпоративных форм в виде праздников, чествований сотрудников и т.п. Трудно сформировать и поддерживать лидерский образ руководителя, которого никто не видит и не слышит;

б) широта возможностей руководителя для поощрения и наказания подчиненных. Руководитель, ограниченный в возможностях поощрять и наказывать своих подчиненных, ограничен в возможности формирования лидерского потенциала среди этих подчиненных. При этом, конечно же, решающее значение для формирования лидерского потенциала имеет не просто наличие возможности поощрять и наказывать, а грамотное использование организационным лидером этих возможностей; в) широта возможностей руководителя решать организационно-социальные, а в особых случаях и личные проблемы и трудности сотрудников. Руководитель, который не может (еще хуже, если не хочет) поддерживать сотрудников в трудные периоды, вряд ли станет для них лидером;

г) наличие и пропаганда социально ориентированных проектов и аспектов деятельности руководителя. На формирование образа руководителя как организационного лидера оказывает влияние не только совершение руководителем «актов лидерства», но и грамотная презентация этих действий. Это может реализовываться посредством организации и информирования сотрудников о социальных проектах в организации, их ознакомления с решениями руководителя, имеющими важное социально-психологическое значение для подчиненных, и т.п.

Таким образом, в структуре лидерского потенциала мы выделили следующие основные компоненты:

- когнитивные компоненты лидера и последователей: лидер и последователи, так или иначе, воспринимают себя и идентифицируют друг друга;

- компетентностно-поведенческие компоненты лидера и последователей: лидер и последователи определенным образом взаимодействуют друг с другом;

- ситуация (условия) осуществления лидерского взаимодействия: взаимодействие лидера и последователей осуществляется в определенных условиях, которые могут способствовать или препятствовать проявлению организационного лидерства. 
В предлагаемой структурной социально-когнитивной модели лидерского потенциала отражены наиболее значимые его компоненты, каждый из которых, на наш взгляд,

\section{Литература}

Джуәлл Л. Индустриально-организационная психология. СПб.: Питер, 2001.

Дрыгина И.В. Активизация лидерского потенциала личности студента в образовательном процессе ВУЗа: Дис. ... канд. пед. наук. Красноярск, 2004.

Емельянова М.Н. Развитие лидерского потенциала детей в процессе исследовательской деятельности: Дис. ... канд. психол. наук. Екатеринбург, 2001.

Кирсанов М.В. Лидерский потенциал антикризисных управляющих: Дис. ... канд. психол. наук. М., 2003. необходимо учитывать при решении задачи формирования (развития) лидерского потенциала руководителя как организационного лидера.

Ожегов С.И., Шведова Н.Ю. Толковый словарь русского языка. М.: Азбуковник, 1999.

Ходаева Е.П. Психолого-акмеологические условия и факторы раскрытия лидерского потенциала политика: Дис. ... канд. психол. наук. М., 2002.

Greenleaf $R$. Servant leadership. Indianapolis, 1991.

Евтихов Олег Владимирович, доцент Сибирского федерального университета (2. Красноярск), кандидат психологических наук

Контакты: evtihov2003@mail.ru 